Vol. 1, No. 1, 2020

Taras Postranskyy, Yuliya Vovk

Lviv Polytechnic National University

Bandery Str. 12, Lviv, Ukraine, 79000

(C) Postranskyy T., Vovk Y., 2020

https://doi.org/10.23939/tt2020.01.012

\title{
CHANGING OF THE BUS DRIVER'S FUNCTIONAL STATE IN CITY CONDITIONS
}

\begin{abstract}
Summary. The functioning of a modern city is impossible without a proper mode of public transport and its network. Parameters of this transport system influence on the functionality of all supply chain links, training specialists, ensuring proper communication between parts of the city, the level of traffic safety, etc. At the same time, all these figures depend also on bus drivers and their work. This is due to the fact that this "human factor" influences on the proper functioning of the public transport system. It should be noted, that one of the indicators that allow analyzing the readiness of the driver to fulfill his direct professional duties is the functional state of his body. Analysis of this indicator allows creating appropriate recommendations for bus driver's schedules of work and rest. According to this, managers can create such working conditions for drivers that will reduce the likelihood of erroneous actions. It will allow reducing the likelihood of road accidents. That's why the importance of researching human as an operator in the transport process is increasing every year.
\end{abstract}

Key words: stress index, heart rate variability, functional state, driving conditions, schedule of driver's work and rest.

\section{INTRODUCTION}

The level of motorization is increasing every year, especially in megapolises and large cities. This is accompanied by the appearance of some negative factors. They are: increasing the level of environmental pollution, the costs of fuel and oil, the probability of traffic accidents, forming traffic jams, etc. But, one of the biggest drawbacks is the decrease in traffic safety. Often the reason for this is an increase in the traffic actually in conflict points at the intersections of streets or roads. Also, the reason can be in high-speed, traffic violations, etc. In all cases, the driver is often the culprit. Because of that, the health and life of all participants of the transport process depends on the driver's actions. However, the statistic shows that among all road accidents those in which the route buses were involved have the greatest consequences. For this reason, every year the task of researching the reliability of the driver's work and creating recommendations that will ensure the proper working conditions becomes more acute.

One of the main documents governing the bus driver's work and rest is the schedule. It's the main planning document for buses work, which contains all decisions about organization of passenger transportation. Based on this document the following approaches can be developed [1]:

- station timetables (for final and intermediate points);

- the work schedule for drivers;

- information schedule for passengers.

The timetable for bus drivers must be created in such a way as to provide [1,2]:

- compliance with traffic safety requirements on the route;

- provision of effective working and rest conditions for drivers;

- comfortable travel conditions for passengers on the route, etc. 
The schedule shows the information about passenger flow on the route, modes of traffic on the road network, parameters of vehicles and driver's data. This document also specifies the release of vehicles taking into account the transportation needs and capabilities of enterprises, the volume of transportation, etc. The schedule determines the mode of operation of each release and the change of drivers, taking into account the necessary interaction in time and distance. Accordingly, the proper compiling of this document will reduce the drivers' emotional and physical load and, as a consequence, reduce the influence of external factors on their functional state and minimize the likelihood of road accidents.

\section{RESEARCH STATEMENT}

The purpose of this research is to identify patterns of change in the bus drivers` functional state, in particular, their stress indexes while working on routes. To achieve this, the following tasks should be accomplished:

- to analyze the bus`s routes on which the studies will be conducted and to form groups of drivers who will participate in the measurements;

- to conduct full-scale studies of the bus drivers' functional state, in particular, to record the indicators of heart rate variability (HRV);

- to analyze the received data and count values of a bus driver`s stress index;

- to establish dynamics of the drivers`stress index changes and to determine relevant patterns.

\section{DRIVER'S FUNCTIONAL STATE, TRAFFIC CONDITIONS AND ROAD SAFETY}

The psychological and physical requirements for the bus driver are based on an analysis of his activity. While driving, he is perceiving the information about: modes and parameters of all road users, environment characteristics, traffic situation, condition of the vehicle parts, etc. At this time, a driver must ensure safe driving on the road. It should be noted that all this process integrates the driver, road, vehicle and the environment into one system in which everything is interconnected. This system is called "drivercar-road-environment" (Fig. 1) [3]

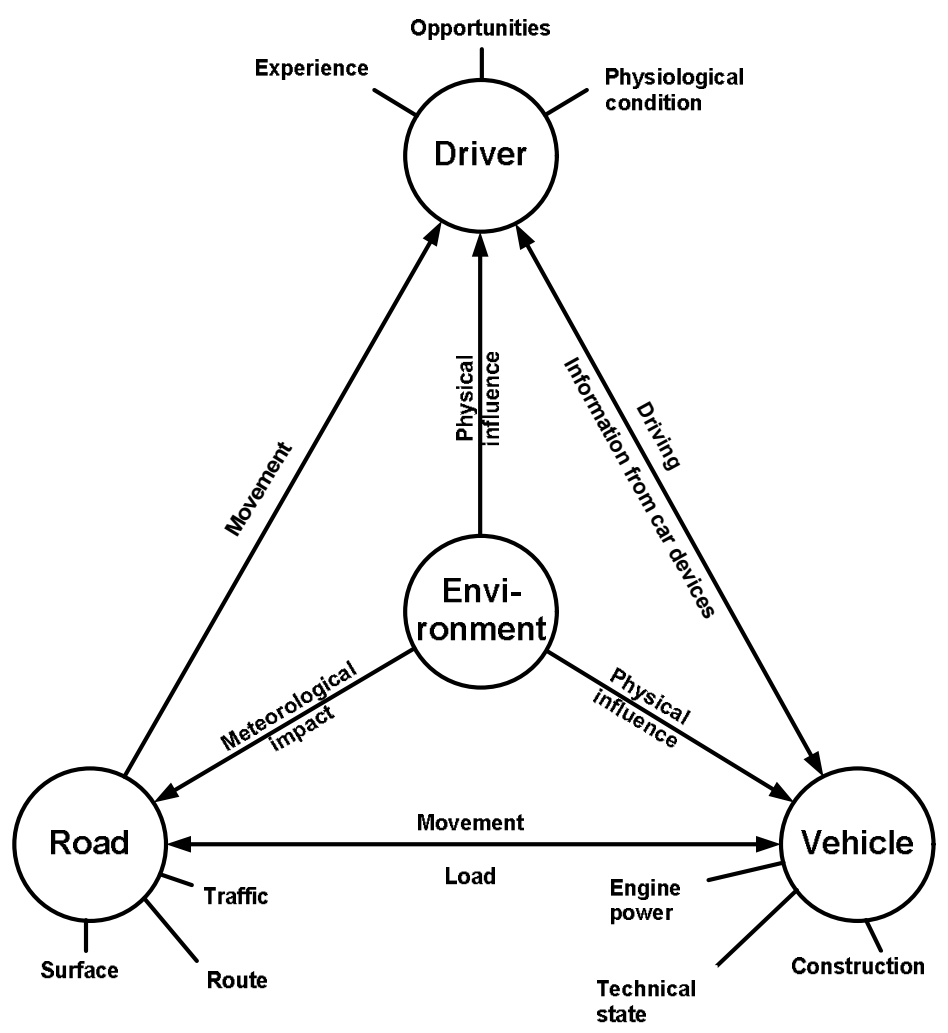

Fig. 1. System "driver-car-road-environment" and its interconnections 
At the same time, the researchers paid much less attention to the reliability of the driver's work, as the probability of an accident, rather than as a function of failure. According to the data presented in articles $[3,4]$, the driver's state affects the reliability of his work. Therefore above-mentioned affect the safety, which can be estimated by the probability of an accident. According to statistics, most accidents are caused by a human's fault, actually because of the driver`s erroneous behavior in critical situations. According to the works of A. Vorkut - proper operation of the transport system depends on the influence of various factors, among which are the psychophysiological qualities of the driver. Also, the importance of the driver in the system "driver - car - road - environment" was confirmed in the scientific works of such scientists: E. Lobanov, J. Briggs, Yu. Davidich, A. Anund, and others. They often noted that the driver is a key link in the above-mentioned system [5-7].

It should be noted that the work of the driver on a city bus route is associated with significant loads on the nervous and emotional systems, responsibility for the safe transportation of passengers, the need to keep track of changes that occur during his work, etc. Because of this, the work of a city bus driver refers to a job with harmful working conditions, according to normative documents [6].

In the process of perceiving a large flow of information, the driver mustn't only recognize it, but also transform and analyze it, then make decisions. The system of factors that determine the complexity of drivers' working conditions is given in the Table $1[8,9]$.

Table 1

The system of factors that determine the complexity of the driver's working conditions

\begin{tabular}{|c|c|}
\hline Factors & Parameters \\
\hline Technical & $\begin{array}{l}\text { The technical state of the vehicle, type of road surface, passenger capacity of the bus, road } \\
\text { condition, length of the vehicle, etc }\end{array}$ \\
\hline Organizational & $\begin{array}{l}\text { Route parameters, transport and passenger flows, the throughput of stopping points, bus lines, } \\
\text { timetables, perform other driver`s duties, etc }\end{array}$ \\
\hline Socio-economic & $\begin{array}{c}\text { Irrational mode of work and rest, regular change of schedules, driving the bus during "rush" } \\
\text { hour, availability of overtime work at any hour of the day, etc }\end{array}$ \\
\hline Ergonomic & $\begin{array}{l}\text { The presence of noise and vibration in the cab and the change of the thermal regime in it } \\
\text { depending on the time of year, the dimension of the cabin and equipment in it, humidity, } \\
\text { ventilation, dust, etc }\end{array}$ \\
\hline Social & $\begin{array}{l}\text { Driver's age, work experience, work mode, duration of working shift, level of work discipline, } \\
\text { the combination of responsibilities, etc }\end{array}$ \\
\hline Psychological & $\begin{array}{l}\text { Dependence of the transportation`s quality on the personal qualities of the driver, high } \\
\text { nervous-emotional tension, high responsibility for the safety of pedestrians and passengers, } \\
\text { concern for the safety of the car, shortage of time to make responsible decisions, etc }\end{array}$ \\
\hline
\end{tabular}

The main idea of different transport researches is increasing in traffic safety. Therefore, nowadays not only "traditional research methods" should be used but also those that consider "human beings" as an important element of the transport process. Because of that, each year's study of the "driver" is increasingly important in transport research. This is due to the fact that the solution to the practical problems posed is largely related to the correct determination of the driver's functional state in different situations.

Usually, the study of the person's functional state is conducted to identify internal diseases and predict trends in their development. If it concerns healthy people, the aim of the study usually is [10]:

- health assessment;

- assessment of the current functional state and the organism`s adaptation reserves;

- professional selection;

- selection of optimal loads during the preparation of individual training plans for athletes;

- detection of overload 's early stages;

- determining the level of performance and its assessment. 
At the present stage of applied physiology`s development, there are different methods of studying the human state which is changing under the influence of different factors. Such changes are considered as a result of the organism's adaptation to the action of external conditions. There are a large number of human functional state research methods, many of which went from sports medicine and the astronauts' professional selection. All of them have such basic requirements [10,11]:

- ensure the safety of human health and life during research;

- not to influence the working conditions of the subject;

- be adequate for the capabilities of the system that is studying;

- be dosed.

Following these requirements, it is possible to determine the influence of different factors on a person's professional activity. The most widely used in the study of the driver's functional state is electrophysiological methods of analysis. The most used of them are [12]:

- electrocardiogram (ECG);

- electroencephalogram;

- electrooculogram;

- galvanic skin response.

This is because not all methods can properly capture the driver's functional state during driving. During the study of the driver's functional state using the devices for recording the ECG, scientists often use mathematical and statistical analysis of HRV as a human's state indicator. With the help of revealed changes in the work of the person's cardiovascular system, it is possible to establish even the smallest changes that occur in its body and, accordingly, the influence of different factors on the functional state. Changes in HRV reflect the body's response to physical and emotional stress, fatigue, etc. HRV analysis it's the study of the R-R intervals in an electrocardiogram, actually, those that reflect normal heart contractions. There are many methods of HRV research and evaluation. The most common of them are: statistical, geometric, spectral analysis, autocorrelation analysis, variational heart rate, etc. In transport's research scientists often use the method of investigating a driver's functional state using a stress index. The calculation of this indicator is carried out according to the following formula [13, 14]:

$$
S I=\frac{A M o}{2 d X \cdot M o},
$$

where $A M o$ - the number of R-R intervals corresponding to the value of mode; $d X$ - the variation range of $\mathrm{R}-\mathrm{R}$ intervals; $M o$ - the R-R interval mode.

According to E. Gavrylov, the driver's functional state by the stress index can be divided into different phases (Table 2). They depend on human performance because it is a value that reflects the functionality of the body $[14,15]$.

Table 2

Phases of the person's functional state [14]

\begin{tabular}{|c|c|c|}
\hline Phases of functional state & Stress index, c.u. & Model marks of operating conditions \\
\hline Great monotony & $<30$ & Unsatisfactorily \\
\hline Moderate monotony & $30-50$ & Satisfactorily \\
\hline Mild monotony & $50-100$ & Good \\
\hline Functional comfort & $100-160$ & Well \\
\hline Tension of adaptation mechanisms & $160-200$ & Good \\
\hline Overstressing adaptation mechanisms & $200-300$ & Satisfactorily \\
\hline Adaptation failure, stress & $>300$ & Unsatisfactorily \\
\hline
\end{tabular}

As can be seen from the data in the Table 2, in determining the driver's functional state, the conditions and duration of its operation must be taken into account. In this case, one of the main 
documents governing the periods' duration of bus`s traffic and it`s downtime is the route schedule. This is a document that takes into account [1]:

- the departure of each vehicle from the park and arrival on the route;

- passage of checkpoints, arrival at final stops and departure from them according to the schedule;

- duration of breaks;

- duration of changes;

- the arrival of the vehicle in the park after the end of work

When such schedules are creating, it must be taking into account that this document should be rational and provide $[1,16]$ :

- high-quality service, creating better conditions for passengers to use public transport and travel with minimal time spent;

- movement of vehicles in accordance with the concentration of passenger flows on routes;

- the regularity of movement;

- coordination of bus movement in accordance with the traffic of other types of public transport.

There are several methods for developing city bus schedules [1]:

- automated;

- graphic;

- stencil;

- tabular.

The automated method of creating the city bus schedule is based on the use of a computer for the necessary calculations and the preparation of a document. The disadvantage of this method is not taking into account the compatible sections of different routes [16].

The graphical method of developing schedules is used for a small number of buses on the route (up to six units) and is mainly used in small towns. This method is based on moving vehicles in coordinates on the route. The slope of the line corresponds to a certain norm of movement's duration and speed. The disadvantage of this method is the narrow scope and neglecting the impact of compatible sections on the route. The advantage of this method is the simple adaptation of it to modern computer technologies, with the help of which we can partially get rid of these drawbacks [16].

The stencil method - it is creating a schedule graphically on a minute movement scale. This method is used alongside with the tabular method to develop a schedule for a large number of bus releases on a route with different systems of work organization for drivers. The minute scale is made by printing tools or by using a special program on the computer. Also, scale paper can be used too [16].

The tabular method is the main method for developing schedules and is used for a large number of buses on the route. The disadvantages of this method are the lack of visual tracking the interval of the units' movement by hours of the day and the need for additional calculations to actually determine the moment of arrival at the final stop. The advantage is the visualization of the departure of each bus during the day [16].

The process of developing the bus's schedules is always time-consuming. It should be noted that the complexity of developing this document is determined by the following factors $[1,16]$ :

- the number of buses releases per route and the feasibility of using them at different periods of the day

- maintenance the route by two or more carriers;

- use of different models of buses on the route depending on the passenger capacity;

- the possibility of providing lunch breaks and stops for drivers at one or both endpoints;

- variable duration of the ride.

Schedules for all types of vehicles in Ukraine must be prepared in accordance with the local law ("Principle on working hours and rest time of wheeled vehicle drivers") that is approved by the Ukrainian Ministry of Infrastructure. According to this document, the driver's working hours include [17]: 
- variable driving period;

- preparatory and final period;

- downtime that is not the fault of the driver;

- duration of downtime at bus stops

- the duration of the medical examination before departure and after returning;

- downtime at the endpoints;

- other periods according to the law of Ukraine.

The development of the bus drivers` work and rest schedules on existing traffic routes should be done according to the following algorithm [16]:

- detailed study of driver`s work features;

- elimination of organizational deficiencies;

- timekeeping with fixation of work and rest periods ;

- study of driver's efficiency changes based on physiological and psychological indicators;

- streamlining work processes and introducing measures to prevent driver fatigue.

That's why it is necessary to investigate the drivers` functional state and take into account the values obtained during the development of the driver's work and rest schedule.

\section{RESEARCH AND ANALYSIS OF THE RESULTS}

In accordance with the purpose of the article, the ECG indicators of drivers who operated buses on urban public transport routes were recorded. Parameters of bus routes are given in the Table 3 .

Table 3

General indicators of the routes on which the research was conducted

\begin{tabular}{|c|c|c|c|c|}
\hline \multirow{2}{*}{ Name of indicators } & \multicolumn{3}{|c|}{ Quantitative indicators of routes } \\
\cline { 2 - 5 } & \multicolumn{2}{|c|}{ The rout №1 } & \multicolumn{2}{c|}{ The rout №2 } \\
\cline { 2 - 5 } & $\begin{array}{c}\text { Direct } \\
\text { direction }\end{array}$ & $\begin{array}{c}\text { Reverse } \\
\text { direction }\end{array}$ & $\begin{array}{c}\text { Direct } \\
\text { direction }\end{array}$ & $\begin{array}{c}\text { Reverse } \\
\text { direction }\end{array}$ \\
\hline The length of the route, km & 6.9 & 7.2 & 24.8 & 24.4 \\
\hline The duration of movement on the rout, min & 45 & 45 & 110 & 110 \\
\hline The number of bus stop points, pcs. & 17 & 15 & - & - \\
\hline The number of bus stations, pcs. & - & - & - & - \\
\hline Dispatch and control points & - & - & - & + \\
\hline
\end{tabular}

It is necessary to note that each rout is radial and connects the peripheral areas of the city with its center. What about drivers, they were driving buses of large capacity, in particular MAZ 203-069. The drivers with different age and work experience are involved in the study. Based on this, they are divided into four groups (Table 4).

Table 4

\section{Characteristics of the drivers who were involved in the study}

\begin{tabular}{|c|c|c|c|c|c|}
\hline Group of drivers & Age of drivers & Work experience & Group of drivers & Age of drivers & Work experience \\
\hline 1 & $30-35$ & $10-15$ & 3 & $41-45$ & $21-25$ \\
\hline 2 & $36-40$ & $16-20$ & 4 & $46-50$ & $>26$ \\
\hline
\end{tabular}

With the help of the Polar H7 device, the necessary HRV indices needed to calculate the voltage index were studied. The device was located in the most stationary area of the chest. The recording was 
done constantly. HRV data were recorded using a mobile device with a Bluetooth adapter. The software "Cardio Mood" was used to record and analyze the required indicators (Fig. 2).
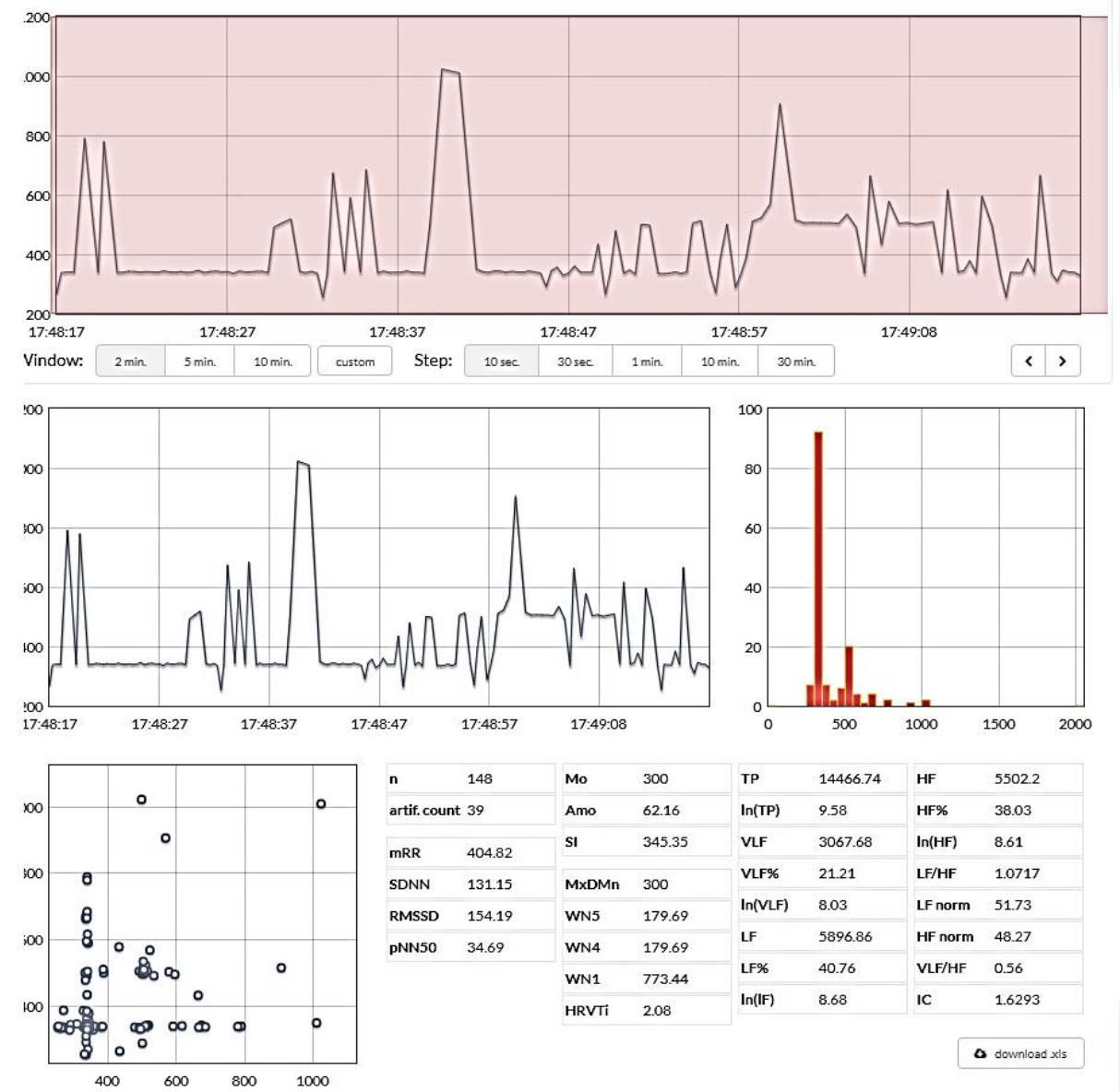

\begin{tabular}{ll|lr} 
TP & 14466.74 & HF & 5502.2
\end{tabular}

\begin{tabular}{ll|ll}
$\operatorname{In}(\mathrm{TP})$ & 9.58 & HF\% & 38.03
\end{tabular}

$\begin{array}{llll}\text { VLF } & 3067.68 & \operatorname{In}(\mathrm{HF}) & 8.61\end{array}$

\begin{tabular}{ll|ll} 
VLF\% & 21.21 & LF/HF & 1.0717
\end{tabular}

\begin{tabular}{ll|ll} 
In(VLF) & 8.03 & LF norm & 51.73
\end{tabular}

\begin{tabular}{ll|ll} 
In(VLF) & 8.03 & LF norm & 51.73 \\
\hline IF & 5896.86 & HF norm & 48.27
\end{tabular}

LF\% $4076 \quad$ VIF/HF 056

\begin{tabular}{ll|ll} 
LF\% & 40.76 & VLF/HF & 0.56 \\
\hline $\operatorname{In}($ IF $)$ & 8.68 & IC & 1.6293
\end{tabular}

Fig. 2. The scheme of driver's HRV fragment, having been analysed in the software environment "Cardio Mood"

Measurements were made at five-minute intervals. Based on the obtained values of the mode and its amplitude and the variation range of the R-R intervals according to the formula (1), the values of the stress index of the drivers' organism during their work on the route were calculated. The data obtained were summarized in tabular form, considering groups of drivers. The average value of this indicator in different periods of drivers` work is given in Table 5 .

Table 5

The average value of the drivers` stress index while working on the route

\begin{tabular}{|c|c|c|c|c|}
\hline \multirow{2}{*}{$\begin{array}{c}\text { The duration of the } \\
\text { study, min }\end{array}$} & \multicolumn{4}{|c|}{ The average value of the drivers` stress index, c.u. } \\
\cline { 2 - 5 } & Group № 1 & Group №2 & Group №3 & Group №4 \\
\hline 1 & 2 & 3 & 4 & 5 \\
\hline 5 & 63.20 & 45.69 & 106.58 & 82.11 \\
\hline 10 & 68.31 & 14.60 & 132.40 & 11.53 \\
\hline 15 & 68.80 & 84.77 & 134.60 & 130.67 \\
\hline 20 & 68.87 & 33.36 & 145.70 & 129.23 \\
\hline 25 & 57.93 & 94.32 & 163.37 & 75.68 \\
\hline 30 & 41.40 & 36.66 & 96.28 & 91.23 \\
\hline 35 & 92.89 & 101.00 & & \\
\hline
\end{tabular}


Table continuation 5

\begin{tabular}{|c|c|c|c|c|}
\hline 1 & 2 & 3 & 4 & 5 \\
\hline 40 & 56.72 & 104.57 & 92.36 & 44.21 \\
\hline 45 & 59.06 & 145.41 & 154.83 & 129.10 \\
\hline 50 & 82.17 & 84.85 & 290.49 & 43.25 \\
\hline 55 & 85.28 & 31.90 & 164.43 & 38.39 \\
\hline 60 & 56.76 & 68.98 & 397.33 & 28.64 \\
\hline 65 & 72.46 & 70.95 & 145.69 & 68.38 \\
\hline 70 & 51.47 & 24.12 & 144.72 & 71.33 \\
\hline 75 & 103.00 & 30.72 & 179.67 & 105.00 \\
\hline 80 & 75.48 & 119.06 & 132.84 & 25.86 \\
\hline 85 & 99.97 & 95.83 & 111.11 & 41.89 \\
\hline 90 & 107.14 & 60.60 & 122.11 & 43.16 \\
\hline 95 & 105.00 & 92.24 & 136.25 & 45.87 \\
\hline 100 & 111.74 & 101.10 & 134.53 & 42.89 \\
\hline 105 & 127.43 & 120.43 & 155.33 & 57.87 \\
\hline 110 & 131.54 & 138.06 & 182.29 & 70.71 \\
\hline 115 & 146.91 & 143.53 & 202.44 & 98.06 \\
\hline 120 & 182.71 & 160.98 & 214.40 & 140.90 \\
\hline
\end{tabular}

Based on these data, the drivers' stress index, which reflects the functional state, is determined. Changing it for $120 \mathrm{~min}$. work on the route is illustrated by Fig. 3.

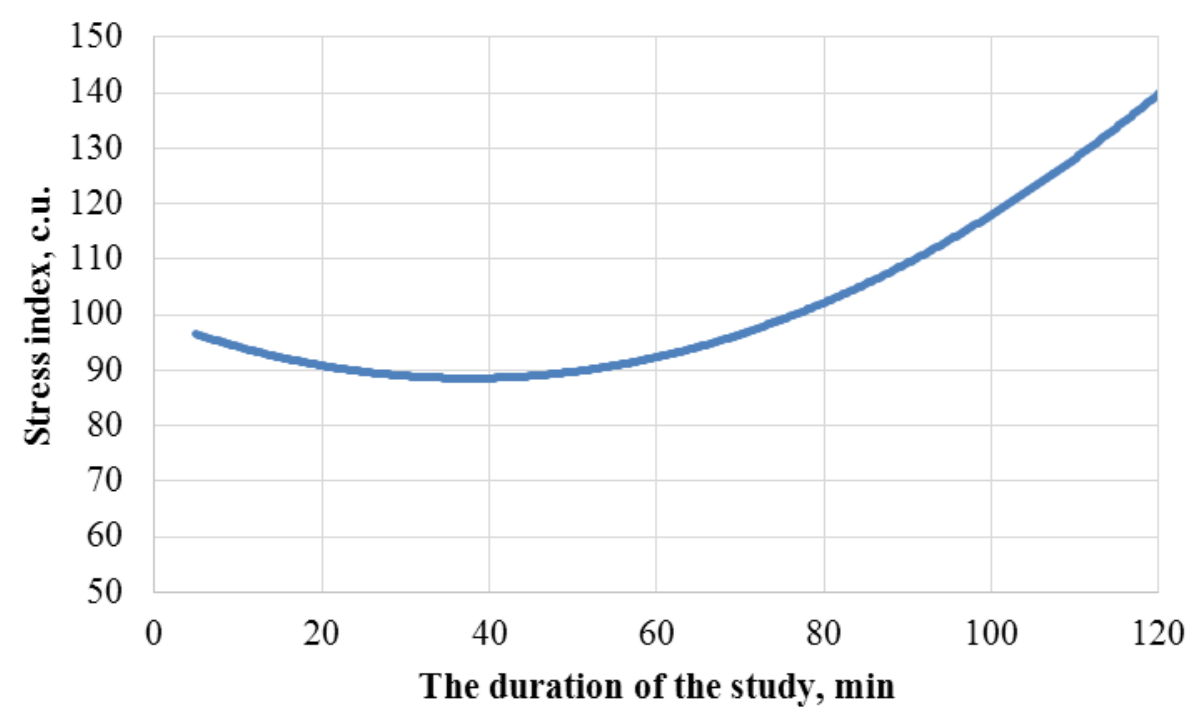

Fig. 3. The average value of all drivers 'stress index while working on the route

In Microsoft Excel software mathematical dependence of bus drivers`stress index during their work on a route is obtained:

$$
S I=0.0075 \cdot t^{2}-0.5654 \cdot t+99.137
$$

where $t$ - duration of work, min.

It should be noted that during the analysis of the obtained data, it was also found that the drivers' stress index of the third group after 110 min. of work was approaching and even exceeding the value of 200 c.u. According to the data given in Table 2, the human body in such a state proceeds to overstress the adaptation mechanisms (>200 c.u.). This can lead to erroneous drivers' decisions that can cause an accident. 


\section{CONCLUSIONS AND RESEARCH PERSPECTIVES}

1. For the study, bus drivers moving on public transport routes with similar parameters were selected. In doing so, the route length, duration, number of stops, etc. were taken into account during analyzing the routes. It should be noted that the research involved drivers whose age ranged from 30 to 50 years, and the bus driving experience was more than 10 years. Using the devices for recording HRV parameters, the bus drivers` stress index was investigated during their operation.

2. Processing of the drivers' HRV indicators during their work, was carried out by main data in laboratory conditions. The online resource "Cardio Mood" was selected as the software environment, which allowed to export the obtained values of mode and its amplitude as well as the variation range of $\mathrm{R}-\mathrm{R}$ intervals into the Microsoft Excel software environment. Based on this, the value of the drivers` stress index, which ranged from 41 to 272 c.u., was obtained. On the basis of the performed researches, a graphical and mathematical model was obtained for changing the drivers' stress index when driving buses on routes. According to the results of the study, it can be stated that during the driving of drivers under such conditions after two hours the value of their stress index can reach 200 c.u. and more. According to the results of the study, it can be stated that when driving route vehicles under such conditions more then two hours, the value of drivers' voltage index can reach 200 c.u. and more. This can adversely affect the speed and correctness of the decision making by the drivers and, as a consequence, lead to the accident. Accordingly, there is a need to investigate drivers' functional state in the performance of their professional duties and to schedule their work and rest, taking into account route indicators, traffic flows, traffic conditions, etc.

\section{References}

1. Bilous A. \& Pivtorak G. (2017). Analiz metodiv vyboru kontrolnykh tochok marshrutu hromadskoho transportu dlia vyznachennia momentu korektsii rozkladu rukhu [Analysis of control point's selection methods of public transport routes for the respective models of the bus schedule's corrections]. Naukovo-vyrobnychyi zhurnal "Avtoshliakhovyk Ukrainy» [Scientific and Industrial Journal "The Avtoshliakhovyk Ukrayiny"], Volume 1-2 (249250), 48 - 51. (in Ukrainian).

2. Joao Mendes-Moreira, Luis Moreira-Matias, Joao Gama \& Jorge Freire de Sousa (2015). Validating the coverage of bus schedules: A Machine Learning approach. Journal "Information Sciences", Volume 293. 299-313. doi: 10.1016/j.ins.2014.09.005 (in English).

3. Stepanov O. (2015). Vplyv psykholohichnoho chynnyka liudyny na bezpeku systemy "Vodii - Avtomobil Doroha - Seredovyshche" [Impact of psychological human factor on safety of the Driver - Automobile - Road Environment system]. Teoriia i praktyka upravlinnia sotsialnymy systemamy [The theory and practice of social systems management], Volume 4, 85-93. (in Ukrainian).

4. Maria Rosaria De Blasiis, Selene Diana \& Valerio Veraldi (2018). Safety audit for weaving maneuver: A driver simulation safety analysis. Journal of Transportation Safety \& Security, Volume 10. Issue 1-2. 159-175. doi: 10.1080/19439962.2017.1323060 (in English).

5. Dolia V. \& Englezi I. (2015). Determine the safe transport of dangerous goods route. Journal of Transport Problems", Volume 10. 31-44. doi: 10.21307/tp-2015-004 (in English).

6. Anund A., Ihlström J., Fors C., Kecklund G. \& Filtness A. (2016). Factors associated with self-reported driver sleepiness and incidents in city bus drivers. Journal "Industrial Health", Volume 54. Issue 4. 337-346. doi: 10.2486/indhealth.2015-0217 (in English).

7. Supriya Goel, Pradeep Tomar, \& Gurjit Kaur. (2016). ECG feature extraction for stress recognition in automobile drivers. Electronic Journal of Biology, Volume 12 (2), 156-165 (in English).

8. Teresa Makowiec-Dąbrowska, Elżbieta Gadzicka, Jadwiga Siedlecka, Agata Szyjkowska, Piotr Viebig, Piotr Kozak \& et al. (2019). Climate conditions and work-related fatigue among professional drivers. International Journal of Biometeorology, Volume 63, 121-1285 (in English).

9. Zuojin Li, Shengbo Eben Li, Renjie Li, \& Jinliang Shi. (2017). Online detection of driver fatigue using steering wheel angles for real driving conditions. Sensors for Transportation, Volume 17 (3), 495. doi: 10.3390/s17030495 (in English).

10. Indresh Verma, Susmita Nath \& Sougata Karmakar (2017). Research in Driver-Vehicle Interaction: Indian Scenario. Ergonomics in Caring for People. 353-361. doi: 10.1007/978-981-10-4980-4_43 (in English). 
11. Kristian Čulik, Alica Kalasova \& Simona Kubikova. (2017). Simulation as an Instrument for Research of Driver-vehicle Interaction. 18th International Scientific Conference - LOGI 2017 Volume 134. doi: 10.1051/matecconf/201713400008 (in English).

12. Lin Wang, Hong Wang, \& Xin Jiang. (2017). A new method to detect driver fatigue based on EMG and ECG collected by portable non-contact sensors. Promet - Traffic\&Transportation, Volume 29, 479-488. doi: 10.7307/ptt.v29i5.2244 (in English).

13. Koichi Fujiwara, Erika Abe, Keisuke Kamata, Chikao Nakayama, Yoko Suzuki, Toshitaka Yamakawa \& et al. (2018). Heart rate variability-based driver drowsiness detection and its validation with EEG. IEEE Transactions on Biomedical Engineering, Volume 66 (6), 1769-1778 (in English).

14. Afonin M.O. (2019). The improvement of technological processes of dangerous goods transportation considering human factor. Candidate's thesis. Lviv: LPNU (in Ukrainian).

15. Hiuliev N. U. (2016). Liudskyi faktor i dorozhni zatory [Human factor and traffic congestion]. Kharkiv: O.M. Beketov NUUE (in Ukrainian).

16. Liujiang Kang, Shukai Chen, Layko, \& Qiang Meng. (2019). Bus and driver scheduling with mealtime windows for a single public bus route. Transportation Research Part C: Emerging Technologies, Volume 101, 145160. doi: 10.1016/j.trc.2019.02.005 (in English).

17. Pro zatverdzhennia Polozhennia pro robochyi chas $i$ chas vidpochynku vodiiv kolisnykh transportnykh zasobiv [On approval of the Regulation on the working time and rest time of wheeled vehicles driver]. Retrieved from https://zakon.rada.gov.ua/laws/show/z0811-10 (in Ukrainian).

Received 24.02.2020; Accepted in revised form 17.03.2020. 